\title{
Elevated alpha1-acid glycoprotein in gastric cancer patients inhibits the anticancer effects of paclitaxel, effects restored by co-administration of erythromycin
}

\author{
Yoshinao Ohbatake ${ }^{1} \cdot$ Sachio Fushida ${ }^{1}$ Tomoya Tsukada ${ }^{1} \cdot$ Jun Kinoshita $^{1}$ • \\ Katsunobu Oyama $^{1}$ - Hironori Hayashi ${ }^{1}$. Tomoharu Miyashita ${ }^{1} \cdot$ Hidehiro Tajima $^{1}$.

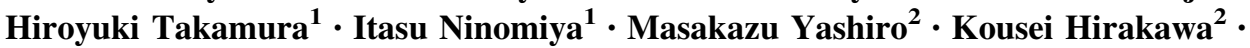 \\ Tetsuo Ohta ${ }^{1}$
}

Received: 13 June 2015/Accepted: 31 August 2015/Published online: 10 September 2015

(C) The Author(s) 2015. This article is published with open access at Springerlink.com

\begin{abstract}
Paclitaxel (PTX) which easily elutes into ascites is widely used to treat gastric cancer patients with peritoneal carcinomatosis (PC), but clinical outcomes are suboptimal. Increased concentrations of $\alpha 1$-acid glycoprotein (AGP), an important drug-binding protein, have been reported in the plasma and ascites of cancer patients. This study sought to clarify whether AGP binds to PTX and alters its anticancer effects. AGP concentrations were measured in the serum and ascites of gastric cancer patients with PC and in the serum of healthy volunteers. The in vitro effects of AGP and AGP plus erythromycin (EM) on PTX were evaluated by MTT assays in the gastric cancer cell lines. We also measured AGP concentrations in the ascites of PC model mice and examined the effects of EM plus PTX on PC. The mean AGP concentrations in the serum and ascites of gastric cancer patients with PC were 1524 and $834 \mu \mathrm{g} / \mathrm{mL}$, respectively, higher than the mean AGP concentration of $650 \mu \mathrm{g} / \mathrm{mL}$ observed in the sera of healthy volunteers. AGP $>400 \mu \mathrm{g} / \mathrm{mL}$ significantly suppressed the cell growth inhibitory effect of PTX in vitro, but the co-administration of EM restored it. Elevated AGP concentrations were observed in the ascites of PC model mice. Administration of PTX alone did not markedly diminish PC, whereas co-administration of PTX and EM significantly reduced PC $(p=0.011)$. AGP is an important
\end{abstract}

Sachio Fushida

fushida@staff.kanazawa-u.ac.jp

1 Department of Gastroenterological Surgery, Kanazawa University Graduate School of Medical Science, 13-1

Takara-machi, Kanazawa 920-8641, Japan

2 Department of Surgical Oncology, Graduate School of Medicine, Osaka City University, 1-4-3 Asahi-machi, Abeno, Osaka 545-8585, Japan regulatory factor modulating the anticancer activity of intraperitoneal PTX. The co-administration of PTX and EM may be effective in treating gastric cancer patients with PC.

Keywords a1-Acid glycoprotein - Gastric cancer . Peritoneal carcinomatosis · Paclitaxel · Erythromycin

$\begin{array}{ll}\text { Abbreviations } \\ \text { PTX } & \text { Paclitaxel } \\ \text { PC } & \text { Peritoneal carcinomatosis } \\ \text { AGP } & \alpha \text {-Acid glycoprotein } \\ \text { EM } & \text { Erythromycin } \\ \text { 5-FU } & \text { 5-Fluorouracil } \\ \text { MST } & \text { Median survival time } \\ \text { IP-PTX } & \text { Intraperitoneal PTX } \\ \text { TGF- } \beta & \text { Transforming growth factor- } \beta \\ \text { DMEM } & \text { Dulbecco's modified Eagle's medium } \\ \text { FBS } & \text { Fetal bovine serum } \\ \text { RPMI } & \text { Roswell Park Memorial Institute } \\ \text { MTT } & \text { 3-(4,5-Dimethylthiazol-2-yl)-2,5- } \\ & \text { diphenyltetrazolium bromide } \\ \text { SD } & \text { Standard deviation } \\ \text { IAP } & \text { Immunosuppressive protein } \\ \text { MRP } & \text { Multidrug resistance-associated protein }\end{array}$

\section{Background}

Gastric cancer is one of the most common malignant diseases worldwide [1]. Although mortality rates have declined, advanced gastric cancer remains life-threatening [2]. Metastasis of gastric cancer frequently includes peritoneal carcinomatosis (PC), and gastric cancer patients with PC have a dismal prognosis [3]. 
In Japan, the standard first-line treatment for patients with advanced gastric cancer consists of $\mathrm{S}-1$, an oral dihydropyrimidine derivative of 5-fluorouracil (5-FU), plus cisplatin [4]. Gastric cancers, however, are only moderately sensitive, and PC is relatively resistant, to systemic chemotherapy. Although few clinical studies have assessed survival in gastric cancer patients with PC, the median survival time (MST) of these patients treated with sequential methotrexate and 5-FU therapy was reported to be 5 months [5]. Paclitaxel (PTX) is often used to treat gastric cancer patients with PC because it can disseminate easily, with a high rate of passage from the systemic circulation into the peritoneal cavity [6]. Intraperitoneal PTX (IP PTX) has been reported successful in several patients $[7,8]$, prompting the ongoing phase III PHOENIX-GC trial, assessing the effectiveness of IP PTX in gastric cancer patients with PC. So it has not been recognized as a standard chemotherapy, and intravenous PTX is a standard now. The randomized phase II JCOG0407 (Japan Clinical Oncology Group) trial was conducted to test the effects of weekly intravenous PTX as second-line treatment in which gastric cancer patients with PC, reported an MST of 7.7 months [9]. To date, therefore, intravenous PTX has not shown satisfactory clinical outcomes in gastric cancer patients with PC.

The abundant presence of fibrous components in PC results in severe complications, including ileus, hydronephrosis, and obstructive jaundice. This is why treating gastric cancer patients with PC is difficult. Thus, the management of fibrosis is also crucial in these patients. Transforming growth factor- $\beta$ (TGF- $\beta$ ) has a pivotal function in the progression of tissue fibrosis. Because lowdose PTX can significantly suppress TGF- $\beta$ signaling and decrease stromal fibrosis [10], PTX should be a key drug in the treatment of gastric cancer patients with PC, making it necessary to increase the antitumor effects of PTX.

Drugs in the peripheral circulation are present as free compounds or bound reversibly to plasma proteins, polysaccharides, and lipids. In general, only the unbound fraction has pharmacodynamic activity because only free, unbound drug in plasma can diffuse across biologic barriers and be transported to their sites of action [11, 12]. A large fraction of PTX binds to serum proteins, including albumin and $\alpha 1$-acid glycoprotein (AGP). In fact, binding data for PTX to AGP were calculated in previous report [13]. AGP, also called orosomucoid, is an acute-phase protein, and changes in its concentration have been found to influence the free plasma concentration of drugs without affecting their total plasma concentrations. Thus, AGP concentration alters the distribution and metabolism of drugs [14]. Serum concentrations of AGP have been found to increase several fold in response to local inflammatory stimuli, and AGP concentrations were observed to increase in both the plasma and ascites of cancer patients [15, 16]. These findings suggested that AGP concentrations are likely elevated in gastric cancer patients, reducing the unbound fraction of PTX. AGP concentrations were reportedly increased in patients with idiopathic pulmonary fibrosis, and increased AGP was found to suppress the activity of the anti-fibrotic agent imatinib. However, erythromycin (EM) can compete with imatinib in binding AGP, abrogating the AGP-mediated inhibition of imatinib [17].

We therefore examined whether the levels of AGP were higher in gastric cancer patients with PC than in normal volunteers and whether AGP inhibited the activity of PTX in vitro. We also assessed whether EM competed with PTX to bind AGP in vitro and in vivo. AGP may be a cause of drug resistance to PTX, and co-administration of PTX and EM, which competes its drug resistance, may be a new encouraging treatment for gastric cancer patients with PC.

\section{Methods}

\section{Reagents}

PTX was purchased from Bristol-Myers Squibb Company (Tokyo, Japan). EM and AGP were purchased from SigmaAldrich Co. (Tokyo, Japan).

\section{Patients}

Serum samples were obtained from 20 gastric cancer patients with PC and from 20 healthy volunteers. Ascites samples were also obtained from 20 gastric cancer patients with PC. This research was performed in accordance with the Declaration of Helsinki. Written informed consent for use of clinical samples and healthy volunteer's samples, as required by the Institutional Review Board at Kanazawa University, Japan, was obtained from all enrolled patients and volunteers.

\section{Cell lines and cell culture}

OCUM-2MD3, a cell line derived from a human scirrhous gastric cancer, with high peritoneal-seeding activity, was kindly provided by the Department of Surgical Oncology of Osaka City University of Medicine. NUGC-3, a cell line derived from human poorly differentiated gastric cancer, was purchased from National Institute of Biomedical Innovation (Osaka, Japan). Cells were seeded in $75-\mathrm{cm}^{2}$ dishes (Becton-Dickinson, Tokyo, Japan). OCUM-2MD3 cells were cultured in 10-mL Dulbecco's modified Eagle's medium (DMEM, Life Technologies, Tokyo, Japan) supplemented with $10 \%$ heat-inactivated fetal bovine serum (FBS) (Nichirei Bioscience Inc., Tokyo, Japan), 100 IU/ 
$\mathrm{mL}$ penicillin, $100 \mathrm{mg} / \mathrm{mL}$ streptomycin (Life Technologies Tokyo, Japan), at $37{ }^{\circ} \mathrm{C}$ in a humidified atmosphere of $5 \% \mathrm{CO}_{2}$ in air. The culture medium for NUGC-3 cells was Roswell Park Memorial Institute (RPMI) 1640 medium (Life Technologies) with $15 \%$ FBS, and the other additives were same as above.

\section{Cell growth assay}

OCUM-2MD3 and NUGC-3 cell viabilities in response to PTX, AGP, and/or EM were determined by standard 3-(4,5-dimethylthiazol-2-yl)-2,5-diphenyltetrazolium bromide (MTT) assays. Cells were seeded at $5 \times 10^{3}$ per well in 96-well plates and incubated for $24 \mathrm{~h}$ at $37^{\circ} \mathrm{C}$ in a humidified environment containing $5 \% \mathrm{CO}_{2}$. These cells were subsequently incubated with PTX, AGP, and EM where indicated, for $48 \mathrm{~h}$; the supernatant was removed; and $100 \mu \mathrm{L}$ of culture medium and $20 \mu \mathrm{L}$ of MTT solution (CellTiter 96 Aqueous One Solution Cell Proliferation Assay; Promega, Tokyo, Japan) were added to each well. These cells were incubated for $3 \mathrm{~h}$, and the absorbance at $490 \mathrm{~nm}$ was analyzed using a microplate reader (Bio-Rad 550; Bio-Rad, Tokyo, Japan). Each sample was assayed in triplicate in each experiment.

\section{Animals and xenograft model}

Male 6-week-old BALB/c nu/nu mice were purchased from Charles River Laboratories Inc. (Yokohama, Japan) housed under specific pathogen-free conditions and fed standard chow pellets and water ad libitum. All experiments adhered to the Standard Guidelines for Animal Experiments at Kanazawa University.

To introduce xenografts into these mice, OCUM-2MD3 cells were harvested from subconfluent cultures, collected by centrifugation, and re-suspended in serum-free DMEM at $1 \times 10^{7}$ cells $/ \mathrm{mL}$, with $1 \times 10^{7}$ cells injected into the peritoneal cavity of each mouse.

\section{AGP analysis}

AGP concentrations in human serum and ascites were determined by nephelometry (SRL Institute, Tokyo, Japan). AGP concentrations in the ascites of nine xenografted mice were examined every 3 days by single radial immunodiffusion assays (Ecos Institute, Ohsaki, Japan).

\section{Co-administration of PTX and EM to mice xenograft}

To evaluate whether EM reactivates the antitumor effects of PTX in vivo, OCUM-2MD3 cells were injected into the peritoneal cavity of mice on day zero. Five mice were administered saline, five received intravenous PTX (5 mg/ $\mathrm{kg}$ each on days 7 and 14), and five received intravenous PTX and subcutaneous EM (5 mg/kg each on days 7-17). All mice were killed on day 17 , and the number and weight of the metastatic nodules were determined.

\section{Statistical analysis}

Values are expressed as mean \pm standard deviation (SD). Data sets were compared using Student's $t$ test or one-way analysis of variance with Tukey's post hoc comparison. Statistical analyses were performed using SPSS statistics 19 software (IBM, Tokyo, Japan), with $p$ values less than 0.05 considered statistically significant.

\section{Results}

\section{Elevated AGP concentrations in serum and ascites of gastric cancer patients with $\mathrm{PC}$}

A comparison of serum AGP concentrations in cancer patients with PC and healthy volunteers found that AGP concentrations were about 2.5-fold higher in the formers than in the latters $(1524 \pm 586$ vs. $650 \pm 158 \mu \mathrm{g} / \mathrm{mL}$, $p=0.0049$ ) (Fig. 1). Although the mean concentration of AGP was higher in ascites of gastric cancer patients with PC than in the serum of healthy volunteer, this difference was not statistically significant.

\section{Elevated AGP concentration in the ascites of a PC model}

To determine whether AGP level changed during cancer progression, AGP concentrations were measured in the

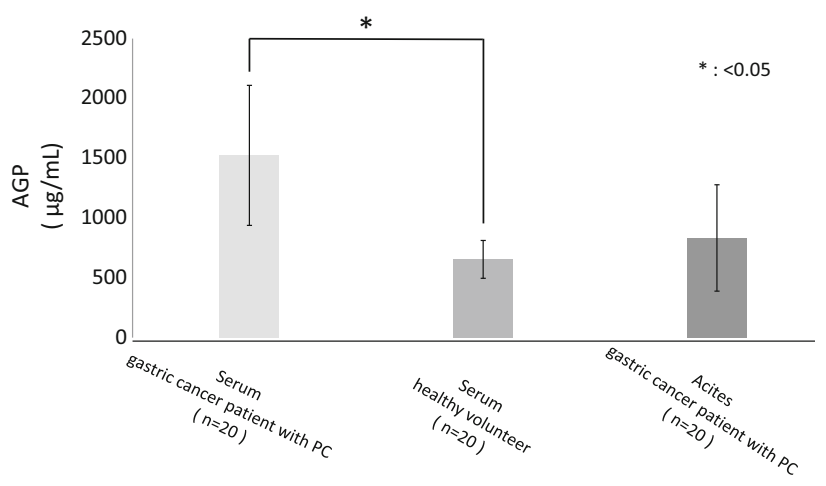

Fig. 1 Concentrations of AGP in the serum of gastric cancer patients with $\mathrm{PC}$ were about 2.5 -fold higher than those of healthy volunteers. The mean concentration of AGP was higher in ascites of gastric cancer patients with PC than in the serum of healthy volunteer, but this difference was not statistically significant. Data are presented as mean $\pm \mathrm{SD}$. ${ }^{*} p<0.05$ versus serum of healthy volunteers 


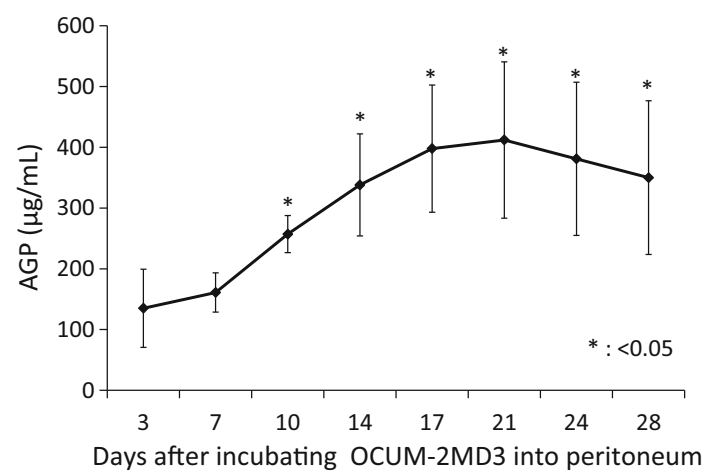

Fig. 2 AGP concentrations in ascites of our xenograft model mouse increased with cancer progression, starting on day 10 and reaching a maximum of $400 \mu \mathrm{g} / \mathrm{mL}$ on day 21. Data are presented as mean \pm SD. $* p<0.05$ versus day 3
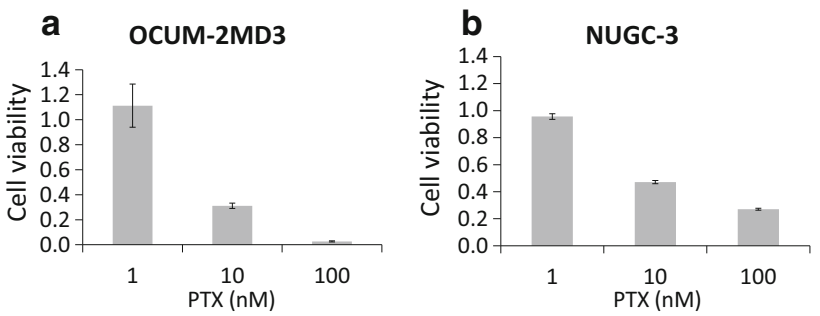

Fig. 3 Effect of PTX was assessed by MTT assays. a OCUM-2MD3 cell viability, b NUGC-3 cell viabilities. Results reported as mean $\pm \mathrm{SD}$ of three independent experiments

ascites fluid of mice intraperitoneally injected with OCUM-2MD3 $\left(1 \times 10^{7}\right)$ cells. AGP concentrations increased with cancer progression, starting on day 10 and reaching a maximum of $400 \mu \mathrm{g} / \mathrm{mL}$ on day 21 (Fig. 2).

\section{AGP inhibits the activity of paclitaxel in vitro}

Using MTT assays, we found that 100 and $10 \mathrm{nM}$ PTX inhibited the growth of OCUM-2MD3 cells and NUGC-3 cells in vitro, whereas $1 \mathrm{nM}$ PTX did not adequately (Fig. 3a, b). We subsequently examined whether $0-1200 \mu \mathrm{g} / \mathrm{mL}$ AGP inhibited the in vitro activity of 10 nM PTX, a concentration equivalent to that in ascites during treatment of patients with intravenous PTX [6]. The addition of AGP suppressed the cell growth inhibitory effect of PTX in a dose-dependent manner, with AGP concentrations higher than $400 \mu \mathrm{g} / \mathrm{mL}$ showing statistically significant effects in both OCUM-2MD3 cells and NUGC3 cells (Fig. 4a, b).

\section{EM competes with PTX for AGP binding in vitro}

To examine the effect of EM on AGP-mediated suppression of PTX's activity in vitro, the viabilities of OCUM-
$2 \mathrm{MD} 3$ cells and NUGC- 3 cells cultured with EM $(0.1,1$, 10 , and $100 \mu \mathrm{M})$, AGP $(800 \mu \mathrm{g} / \mathrm{mL})$, and PTX $(10 \mathrm{nM})$ were determined using MTT assays. We also examined whether EM without AGP affected the cell growth inhibitory effect of PTX. The addition of EM in a high-AGP environment significantly reactivated the cell growth inhibitory effect of PTX in a dose-dependent manner (Fig. 5a, b). In contrast, EM without AGP did not affect the cell growth inhibitory effect of PTX (Fig. 6).

\section{Co-administration of EM enhances the antitumor effects of PTX in a mouse PC model}

PTX alone or PTX plus EM tended to reduce the number of peritoneal nodules in mice, but the differences were not statistically significant. In contrast, PTX plus EM, but not PTX alone, significantly reduced the weight of metastatic nodules (Fig. 7a, b).

\section{Discussion}

This study showed that AGP concentrations in the ascites fluid of a mouse model of gastric cancer with PC increased with cancer progression and that elevated AGP suppressed the cell growth inhibitory effects of PTX. We also demonstrated that co-administration of EM, which competed with PTX to bind AGP, restored the cell growth inhibitory effects of PTX in vitro and in vivo.

Many drugs bind reversibly to serum proteins, with bound and unbound fractions being in equilibrium. AGP is an important drug-binding protein, with a molecular weight of around $43 \mathrm{kDa}$ [18]. AGP is negatively charged at physiological $\mathrm{pH}$, and binds mostly basic drugs. AGP is thought to contain three subunits at its drug-binding site; these subunits were not completely separated but significantly overlapped and influenced one another, enabling AGP to bind acidic, basic, and neutral drugs [19-22].

The physiological role of AGP is still not completely understood. Immunosuppressive protein (IAP), a type of AGP, has also been found in the serum and ascites of cancer patients, and IAP has been reported to suppress several immune responses including phytohemagglutinininduced lymphocyte blast formation and mixed lymphocyte reactions [23]. Elevated IAP may trigger the induction of suppressive macrophages [24]. Moreover, serum IAP concentration in gastric cancer patients has been reported to increase with advancing cancer stage, suggesting that IAP may be useful in estimating the immunological status of these patients [25]. Elevated AGP may have a similar function, inducing immune tolerance in gastric cancer patients. 
Fig. 4 Effect of AGP $(0-1200 \mu \mathrm{g} / \mathrm{mL})$ on PTXsuppressed conditions was assessed by MTT assays. a OCUM-2MD3 cell viability, b NUGC-3 cell viability. Results reported as mean $\pm \mathrm{SD}$ of three independent experiments. $* p<0.05$ versus cells added culture medium alone
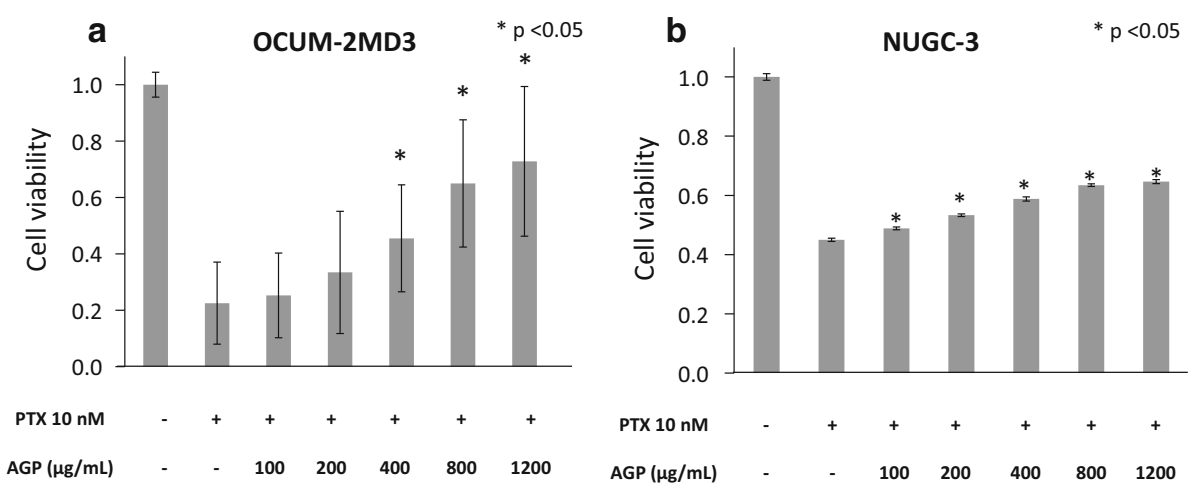

Fig. 5 Effect of the coadministration of PTX and EM on OCUM-2MD3 and NUGC-3 cell viabilities in a high-AGP environment was determined using MTT assays. OCUM2MD3 and NUGC-3 cells were incubated with $\operatorname{EM}(0.1,1,10$, $100 \mu \mathrm{M})$, AGP $(800 \mu \mathrm{g} / \mathrm{mL})$, and PTX (10 nM), and cell viabilities were measured. Data are presented as mean \pm SD of three independent experiments. $* p<0.05$ versus cells treated with PTX and AGP

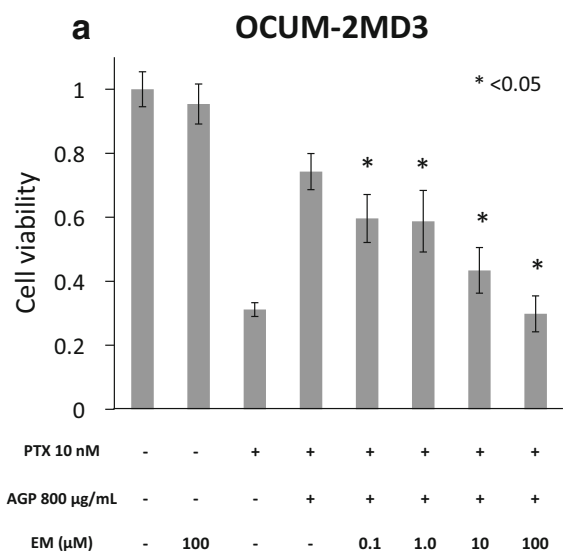

\section{b}

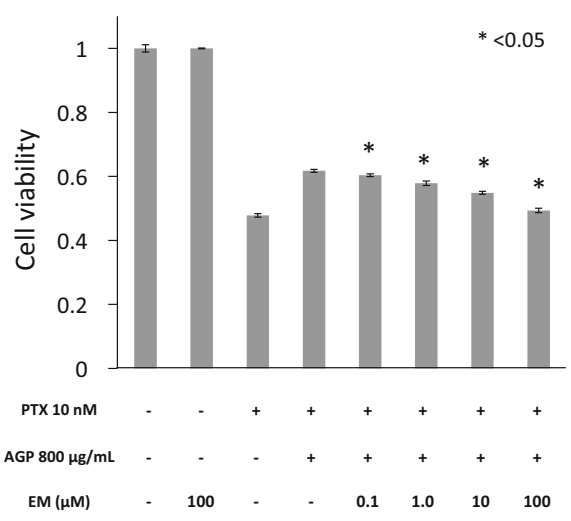

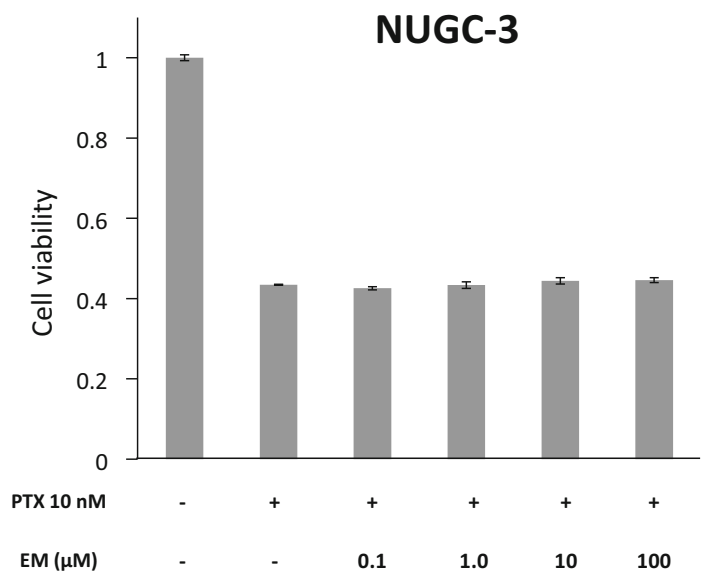

Fig. 6 Effect of co-administration of PTX and EM without AGP on NUGC-3 cell viability was determined using MTT assays. NUGC-3 cells were incubated with $\mathrm{EM}(0.1,1,10,100 \mu \mathrm{M})$, and PTX $(10 \mathrm{nM})$, and cell viabilities were measured. The difference of cell viability between the group treated with PTX alone and the groups treated with PTX plus EM was not statistically significant. Data are presented as mean $\pm \mathrm{SD}$ of three independent experiments

PTX is widely used to treat gastric cancer patients, especially those with PC, but its efficacy is suboptimal. PTX metabolism is catalyzed mainly by CYP3A4 and 2C8 $[26,27]$, and it is substrate for ATP-binding cassette transporter such as P-glycoprotein and multidrug resistance-associated protein (MRP) [28, 29]. The competition for these enzymes or overexpression of these transporters causes drug resistance to PTX. EM undergoes extensive hepatic metabolism and is metabolized by CYP3A4 and substrate for P-glycoprotein and MRP affecting metabolism of another drugs [30]. In our study, changing the concentration of EM without AGP did not affect the cell growth inhibitory effect of PTX, while co-cultured with AGP reactivated PTX in a dose-dependent manner. This means EM did not potentiate PTX by the way of CYP3A4, P-glycoprotein, or MRP, but the way of competing with PTX for binding AGP. In brief, increased AGP is associated with the drug resistance to PTX. This is consistent with previous reports that AGP inhibited the activity of molecularly targeted drug and another anticancer drug [17, $31,32]$. The binding of drug to serum proteins is an important determinant of the pharmacokinetics. For drugs that circulate mostly in a bound state, even a small change in the extent of protein binding can have a large effect on drug activity. AGP may have great influence on PTX, because about $90 \%$ of this drug binds to plasma proteins [33]. The mean AGP concentration in the ascites of gastric cancer patients was $834 \mu \mathrm{g} / \mathrm{mL}$, which was higher than in the serum of healthy volunteers. Moreover, AGP 


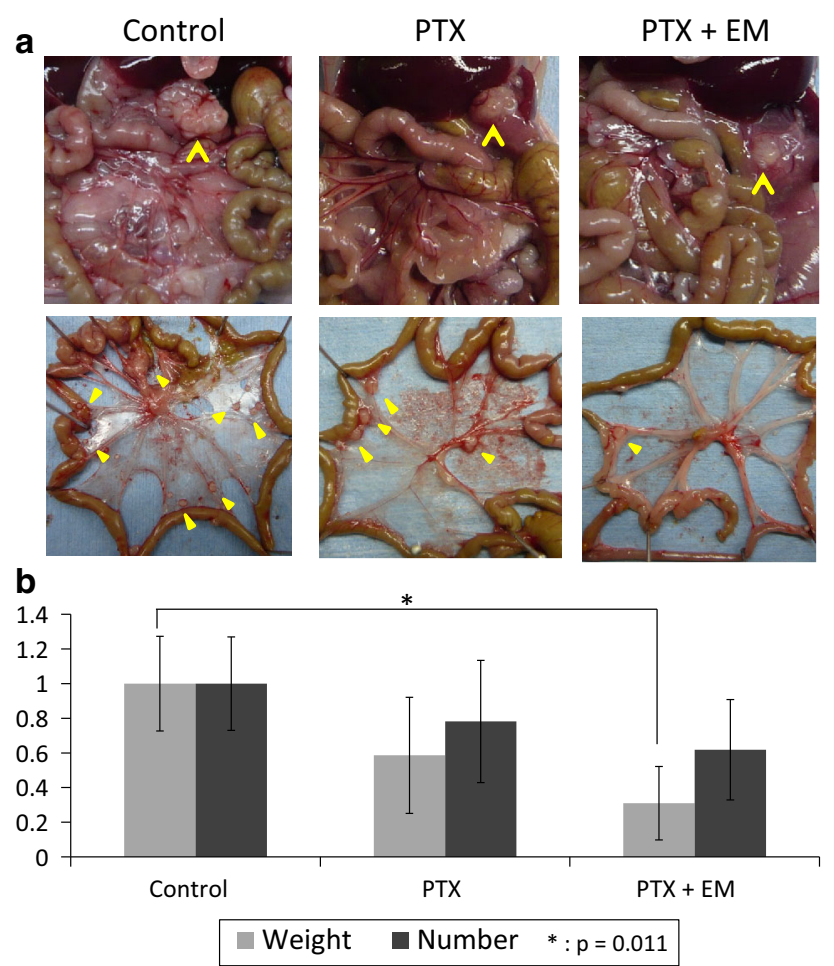

Fig. 7 Xenograft model was made by incubating OCUM-2MD3 into nu/nu mice intraperitoneally. Effect of PTX plus EM on metastatic nodules was assessed. a Macroscopic views of peritoneal nodules (arrow head). b Relative number and weight of metastatic peritoneal nodules in the xenograft model. Data are shown as mean \pm SD. $* p<0.05$ versus untreated group

concentration in mouse ascites increased with the growth of the peritoneal nodules. These results suggest that AGP concentrations in the ascites of gastric cancer patients increase with tumor progression, a finding consistent with result showing that AGP concentration in a mouse model of leukemia increased in proportion to tumor load [31].

We found that AGP $>400 \mu \mathrm{g} / \mathrm{mL}$ significantly inhibited the activity of $10 \mathrm{nM}$ PTX in vitro. Because the mean AGP concentration in the ascites of gastric cancer patients with PC was $834 \mu \mathrm{g} / \mathrm{mL}$, the activity of intravenously administered PTX may be suppressed by elevated AGP in the peritoneal cavity. PTX concentrations in the ascites of advanced gastric cancer patients, who were administered $80 \mathrm{mg} / \mathrm{m}^{2}$ of PTX intravenously, were reported to be $35 \mathrm{nM}$ after $12 \mathrm{~h}$ and $14 \mathrm{nM}$ after $72 \mathrm{~h}$ [6]. In vitro, we found that $10 \mathrm{nM}$ of PTX was inhibited by AGP, indicating that the antitumor effect of intravenous PTX in the peritoneal cavity of gastric cancer patients would be suppressed by elevated AGP.

The addition of another agent to the primary antitumor drug may increase the antitumor effect or decrease the side effects of the latter. This process, called biochemical modulation, is thought to be due to the second agent, called the "modulator," altering the pharmacokinetics and/or metabolism of the antitumor agent. For example, 5-FU or methotrexate has been administered together with leucovorin. To reactivate the antitumor effect of PTX that was suppressed by AGP, we added EM as a modulator. Fourteen-membered macrolides, including EM, have been reported to compete with molecularly targeted drugs in binding AGP and restoring their activity $[16,30]$. We found that EM concentrations $>0.1 \mu \mathrm{M}$ significantly reactivated the cell growth inhibitory effect of PTX $(10 \mathrm{nM})$ suppressed by AGP $(800 \mu \mathrm{g} / \mathrm{mL})$. These concentrations of EM are equivalent to the serum concentrations resulting from the administration of standard dosages to mice and humans [34-36]. Finally, we demonstrated that co-administration of PTX and EM was more effective than PTX alone in the PC mouse model. The negative effect of AGP and the positive one of EM are predicted to be applied not only to the cancer cells but also to the normal cells. However, they have probably little effect on normal cells because PTX originally provides antitumor effect inhibiting active cell division of cancer cells rather than normal cells. Actually, PTX $>10 \mathrm{nM}$ shows about threefold of the cell growth inhibitory effect in gastric cancer cell than in human peritoneal mesothelial cells which mostly exists in peritoneal cavity [10]. Intravenous administration of $80 \mathrm{mg} / \mathrm{m}^{2}$ PTX reaches over $1.7 \times 10^{3} \mathrm{nM}$ in plasma [6]. Figure 3 in our study showed even $1 \times 10^{2} \mathrm{nM}$ PTX suppressed the cell growth inhibitory effect very well. $1.7 \times 10^{3} \mathrm{nM}$ PTX may be still more effective and unaffected by AGP or EM because of large free fraction of PTX. For this reason, negative effect of AGP and positive one of EM on cancer cells and normal cells may not be seen in whole body through peripheral circulation. In the previous report, when ovarian cancer patients with various AGP concentrations were treated with intravenous PTX modulating its pharmacokinetics by clindamycin binding to AGP, their toxicity was not increased [37].

The mechanism underlying the elevation in AGP concentrations observed in gastric cancer patients with PC remains unclear. AGP is synthesized mainly by hepatocytes in response to inflammation. Gastric cancer patients with PC are in a state of chronic inflammation, which may increase AGP levels. AGP concentrations have also been reported high in patients with idiopathic pulmonary fibrosis, but there were no correlations between AGP and C-reactive protein concentrations [17]. Elevations in AGP may also be due to a non-inflammatory mechanism. Extrahepatic synthesis of AGP has been reported [38], and AGP has been detected in malignant human tissue including stomach tumors [39]. Gastric cancer cells may produce AGP, and co-administration of PTX and EM may be effective in such a high-AGP environment. 


\section{Conclusions}

Co-administration of PTX and EM, which competes to bind AGP, might be an encouraging treatment for patients with metastatic advanced gastric cancer. Clinical trials are being planned to evaluate the effectiveness of EM supplementation in enhancing the effects of weekly PTX therapy for gastric cancer patients with PC.

Acknowledgments This study was supported in part by grants-inaid for Scientific Research (C; 25462015 to S.F.) from the Japan Society for the Promotion of Science (JSPS).

\section{Compliance with ethical standards}

Conflict of interest The authors declare that they have no conflict of interest.

Ethical approval All procedures performed in studies involving human participants were in accordance with the ethical standards of the institutional and/or national research committee and with the 1964 Helsinki Declaration and its later amendments or comparable ethical standards.

Human and animal rights All procedures performed in studies involving human participants were in accordance with the ethical standards of the institutional review board at Kanazawa University and with the 1964 Helsinki declaration and its later amendments or comparable ethical standards. All procedures performed in studies involving animals adhere to the Standard Guidelines for Animal Experiments at Kanazawa University.

Informed consent Informed consent was obtained from all individual participants included in the study.

Open Access This article is distributed under the terms of the Creative Commons Attribution 4.0 International License (http://crea tivecommons.org/licenses/by/4.0/), which permits unrestricted use, distribution, and reproduction in any medium, provided you give appropriate credit to the original author(s) and the source, provide a link to the Creative Commons license, and indicate if changes were made.

\section{References}

1. Jemal A, Bray F, Center MM, Ferlay J, Ward EFD. Global cancer statistics. A Cancer J Clin. 2011;61:69-90.

2. Bertuccio $\mathrm{P}$, Chatenoud L, Levi F, et al. Recent patterns in gastric cancer : a global overview. Int J Cancer. 2009;125:666-73.

3. Okabe H, Ueda S, Obama K, Hosogi H, Sakai Y. Induction chemotherapy with S-1 plus cisplatin followed by surgery for treatment of gastric cancer with peritoneal dissemination. Ann Surg Oncol. 2009;16:3227-36.

4. Koizumi W, Narahara H, Hara T, et al. S-1 plus cisplatin versus S-1 alone for first-line treatment of advanced gastric cancer (SPIRITS trial): a phase III trial. Lancet Oncol. 2008;9:215-21.

5. Yamao T, Shimada Y, Shirao K, et al. Phase II study of sequential methotrexate and 5-fluorouracil chemotherapy against peritoneally disseminated gastric cancer with malignant ascites: a report from the Gastrointestinal Oncology Study Group of the Japan Clinical Oncology Group, JCOG 9603 Trial. Jpn J Clin Oncol. 2004;34:316-22.
6. Kobayashi M, Sakamoto J, Namikawa T, et al. Pharmacokinetic study of paclitaxel in malignant ascites from advanced gastric cancer patients. World J Gastroenterol. 2006;12:1412-5.

7. Tamura S, Miki H, Nakata K, et al. Intraperitoneal administration of paclitaxel and oral S-1 for a patient with peritoneal dissemination and hydronephrosis due to advanced gastric cancer. Gastric Cancer. 2007;10:251-5.

8. Ishigami H, Kitayama J, Kaisaki S, et al. Phase II study of weekly intravenous and intraperitoneal paclitaxel combined with S-1 for advanced gastric cancer with peritoneal metastasis. Ann Oncol. 2010;21:67-70.

9. Takiuchi H, Fukuda H, Boku N, et al. Randomized phase II study of best-available 5-fluorouracil (5-FU) versus weekly paclitaxel in gastric cancer (GC) with peritoneal metastasis (PM) refractory to 5-FU-containing regimens (JCOG0407). J Clin Oncol 2010;28:15(suppl; abstr 4052).

10. Tsukada T, Fushida S, Harada S, et al. Low-dose paclitaxel modulates tumour fibrosis in gastric cancer. Int $\mathbf{J}$ Oncol. 2013;42:1167-74.

11. Lima JJ, Boudoulas H, Blanford M. Concentration-dependence protein and its influence of disopyramide binding to on kinetics and dynamics 1. J Pharmacol Exp Ther. 1981;219:741-7.

12. Stewart CF, Arbuck SG, Fleming R, Evans WE. Relation of systemic exposure to unbound etoposide and hematologic toxicity. Clin Pharmacol Ther. 1991;50:385-93.

13. Finlay GJ, Baguley BC. Effects of protein binding on the in vitro activity of antitumour acridine derivatives and related anticancer drugs. Cancer Chemother Pharmacol. 2000;45(5):417-22.

14. Routledge PA. The plasma protein binding of basic drugs. Br J Clin Pharmacol. 1986;22:499-506.

15. Piver MS, Moyer M, Diakun K, Lele SB, Chu TM. Serum alpha1acid glycoprotein in epithelial ovarian cancer. Gynecol Oncol. 1988;29:305-8.

16. Elg SA, Mayer AR, Carson LF, Twiggs LB, Hill RB, Ramakrishnan S. Alpha-1 acid glycoprotein is an immunosuppressive factor found in ascites from ovaria carcinoma. Cancer. 1997;80:1448-56.

17. Azuma M, Nishioka Y, Aono Y, et al. Role of alpha1-acid glycoprotein in therapeutic antifibrotic effects of imatinib with macrolides in mice. Am $J$ Respir Crit Care Med. 2007; 176:1243-50.

18. Filip Z, Jan K, Vendula S, Jana KZ, Kamil M, Kamil K. Albumin and $\alpha 1$-acid glycoprotein: old acquaintances. Expert Opin Drug Metab Toxicol. 2013;9:943-54.

19. Otagiri M, Miyoshi T, Yamamichi R, Maruyama T, Perrin JH. Effects of tricyclic drug on induced circular dichroism spectra of dicumarol bound to $\alpha 1$-acid glycoprotein. Biochem Pharmacol. 1991;42:729-33.

20. Miyoshi T, Yamamichi R, Maruyama T, Otagiri M. Reversal of signs of induced cotton effects of dicumarol-alpha 1-acid glycoprotein systems by phenothiazine neuroleptics through ternary complexation. Pharm Res. 1992;9:845-9.

21. Miyoshi T, Yamamichi R, Maruyama T, Takadate A, Otagiri M. Further characterization of reversal of signs of induced cotton effects of dicumarol derivatives-alpha 1-acid glycoprotein systems by protriptyline. Biochem Pharmacol. 1992;43:2161-7.

22. Otagiri M. A molecular functional study on the interactions of drugs with plasma proteins. Drug Metab Pharmacokinet. 2005;20:309-23.

23. Tamura K, Shibata Y, Matsuda Y, Ishida N. Isolation and characterization of an immunosuppressive acidic protein from ascitic fluids of cancer patients isolation and characterization of an immunosuppressive. Cancer Res. 1981;41:3244-52.

24. Shibata Y, Tamura K, Ishida N. In vivo analysis of the suppressive effects of immunosuppressive acidic protein, a type of alpha 1-acid glycoprotein, in connection with its high level in tumor-bearing mice. Cancer Res. 1983;43:2889-96. 
25. Shimizu N, Yamane $\mathrm{T}$, Karino $\mathrm{T}$, et al. Immunosuppressive acidic protein (IAP) in gastric cancer patients. Jpn J Surg. 1983;13:312-6.

26. Harris JW, Rahman A, Kim BR, Guengerich FP, Collins JM. Metabolism of taxol by human hepatic microsomes and liver slices: participation of cytochrome P450 3A4 and an unknown P450 enzyme. Cancer Res. 1994;54(15):4026-35.

27. Rahman A, Korzekwa KR, Grogan J, Gonzalez FJ, Harris JW. Selective biotransformation of taxol to 6 alpha-hydroxytaxol by human cytochrome P450 2C8. Cancer Res. 1994;54(21):5543-6.

28. Rahman A, Korzekwa KR, Grogan J, Gonzalez FJ, Harris JW. Selective biotransformation of taxol to 6 alpha-hydroxytaxol by human cytochrome P450 2C8. Cancer Res. 1994;54(21):5543-6.

29. Sparreboom A A, van Asperen J, Mayer U, et al. Limited oral bioavailability and active epithelial excretion of paclitaxel (Taxol) caused by P-glycoprotein in the intestine. Proc Natl Acad Sci USA. 1997;94(5):2031-5.

30. Huisman MT, Chhatta AA, van Tellingen O, Beijnen JH, Schinkel AH. MRP2 (ABCC2) transports taxanes and confers paclitaxel resistance and both processes are stimulated by probenecid. Int J Cancer. 2005;116(5):824-9.

31. Franke RM, Lancaster CS, Peer CJ, et al. Effect of ABCC2 (MRP2) transport function on erythromycin metabolism. Clin Pharmacol Ther. 2011;89(5):693-701.

32. Bruno R, Olivares R, Berille J, et al. Alpha-1-acid glycoprotein as an independent predictor for treatment effects and a prognostic factor of survival in patients with non-small cell lung cancer treated with docetaxel. Clin Cancer Res. 2003;9:1077-82.

33. Finlay GJ, Baguley BC. Effects of protein binding on the in vitro activity of antitumour acridine derivatives and related anticancer drugs. Cancer Chemother Pharmacol. 2000;45:417-22.

34. Conte JE, Golden JA, Duncan S, McKenna E, Zurlinden E. Intrapulmonary pharmacokinetics of clarithromycin and of erythromycin. Antimicrob Agents Chemother. 1995;39:334-8.

35. Männistö PT, Hanhijärvi H, Havas A, Vuorela A, Komulainen H, Rauramaa V. Efficacy of erythromycin acistrate (2'-acetyl erythromycin stearate) and erythromycin stearate in experimental infections in mice. J Pharmacol Exp Ther. 1989;250:1028-33.

36. Pai SR, Singh KV, Murray BE. In vivo efficacy of the ketolide ABT-773 (cethromycin) against enterococci in a mouse peritonitis model. Antimicrob Agents Chemother. 2003;47:2706-9.

37. Fruscio R, Lissoni AA, Frapolli R, et al. Clindamycin-paclitaxel pharmacokinetic interaction in ovarian cancer patients. Cancer Chemother Pharmacol. 2006;58(3):319-25.

38. Fournier T, Medjoubi-N N, Porquet D. Alpha-1-acid glycoprotein. Biochim Biophys Acta. 2000;1482:157-71.

39. Twining SS, Brecher AS. Identification of alpha 1-acid glycoprotein, alpha2-macroglobulin and antithrombin III as components of normal and malignant human tissues. Clin Chim Acta. 1977;75:143-8. 